\title{
A New Metallographic Technique for Revealing Grain Boundaries in Aluminum Alloys
}

\author{
M. Mohammadtaheri
}

Received: 1 April 2012/Revised: 9 August 2012/Published online: 6 October 2012

(C) Springer Science+Business Media New York and ASM International 2012

\begin{abstract}
A new metallographic technique has been developed for revealing the grain structure of common 5000 and 2000-series aluminum alloys. Grain structures of these aluminum alloys are normally difficult to reveal with common etchants. The preferred metallographic etchant for structural aluminum alloys is generally based on $\mathrm{HCl}$, $\mathrm{HNO}_{3}$, and $\mathrm{HF}$, usually referred to as Keller's reagent. At times, however, this etchant does not give completely satisfactory results. This is true when the structure is inhomogeneous, having patches of recrystallized and nonrecrystallized grains, or clusters of intermetallic particles in material containing few particles. Samples with a poor final polish and a smeared surface also do not respond well to Keller's etchant. The new technique described in this article consists of two steps: 1 . a pre etchant with a solution of $1 \mathrm{~g} \mathrm{NaCl}$ in $50 \mathrm{ml} \mathrm{H}_{3} \mathrm{PO}_{4}(40 \%)$ and 2. etch with Weck's reagent. The microstructures obtained with this new method are compared with Keller's and Weck's reagents.
\end{abstract}

Keywords Reagent $\cdot$ Aluminum alloys $\cdot$ Microstructure

\section{Introduction}

Determination of grain size, shape, and distribution in polycrystalline materials is one of the most important metallographic measurements because of the influence of grain size on mechanical properties. Many methods are available to reveal grain structure of aluminum and its

M. Mohammadtaheri $(\square)$

Department of Materials Science and Engineering, Ferdowsi

University of Mashhad, 91775-1111 Mashhad, Iran

e-mail: msctaheri@gmail.com alloys, for example, chemical etching and anodizing techniques. However, chemical etching methods using etchants such as $\mathrm{HF}(0.5 \%)$, Keller's reagent and $\mathrm{HNO}_{3}$ at $70{ }^{\circ} \mathrm{C}$ do not always yield high grain boundary contrast [1]. This is attributed to grain orientation and the resultant variation in depth of grain boundary steps, caused by variations in rate of chemical attack between neighboring grains. As result, not all grain boundaries are clearly delineated.

Grain contrast also varies with alloys and heat treatment conditions when standard chemical etching and anodizing techniques are used. If the grain structure of an anodized sample is very fine (e.g., $<10 \mu \mathrm{m}$ ), color contrast between neighboring grains on a color photograph or gray-scale contrast on a black-and-white photograph taken at a required high magnification becomes so low that an accurate measurement of grain size is almost impossible. Therefore, an improved technique for revealing grain structures of aluminum alloys is needed [2]. In this article, a new metallographic technique is demonstrated for revealing grain boundaries of common 2000 and 5000 series aluminum alloys.

\section{Etching Technique}

Samples of 5083 alloy in two different conditions (annealed (O) and 30\% cold worked) and samples of the 2024 alloy in the annealed (O) and artificial age-hardened (T6) condition were used to illustrate the etching technique. Chemical compositions of samples are given in Table 1. The new technique consists of two steps. The samples were first pre-etched for $3 \mathrm{~min}$ in a solution of $1 \mathrm{~g}$ $\mathrm{NaCl}$ in $50 \mathrm{~mL} \mathrm{H}_{3} \mathrm{PO}_{4}(40 \%)$ at $70{ }^{\circ} \mathrm{C}$. Then, samples were etched with Weck's reagent $\left(100 \mathrm{~mL} \mathrm{H}_{2} \mathrm{O}+1 \mathrm{~g}\right.$ $\left.\mathrm{NaOH}+4 \mathrm{~g} \mathrm{KMnO}_{4}\right)$. After etching, the samples were 
Table 1 Chemical composition of 2024 and 5083 alloys

\begin{tabular}{llllllllll}
\hline Alloy & $\mathrm{Fe}$ & $\mathrm{Si}$ & $\mathrm{Cu}$ & $\mathrm{Mn}$ & $\mathrm{Mg}$ & $\mathrm{Zn}$ & $\mathrm{Ti}$ & $\mathrm{Cr}$ & $\mathrm{Al}$ \\
\hline 2024 & 0.4 & 0.41 & 4.5 & 0.5 & 1.5 & 0.2 & 0.12 & 0.07 & Remainder \\
5083 & 0.29 & 0.10 & 0.04 & 0.80 & 4.52 & 0.11 & 0.006 & 0.05 & Remainder \\
\hline
\end{tabular}
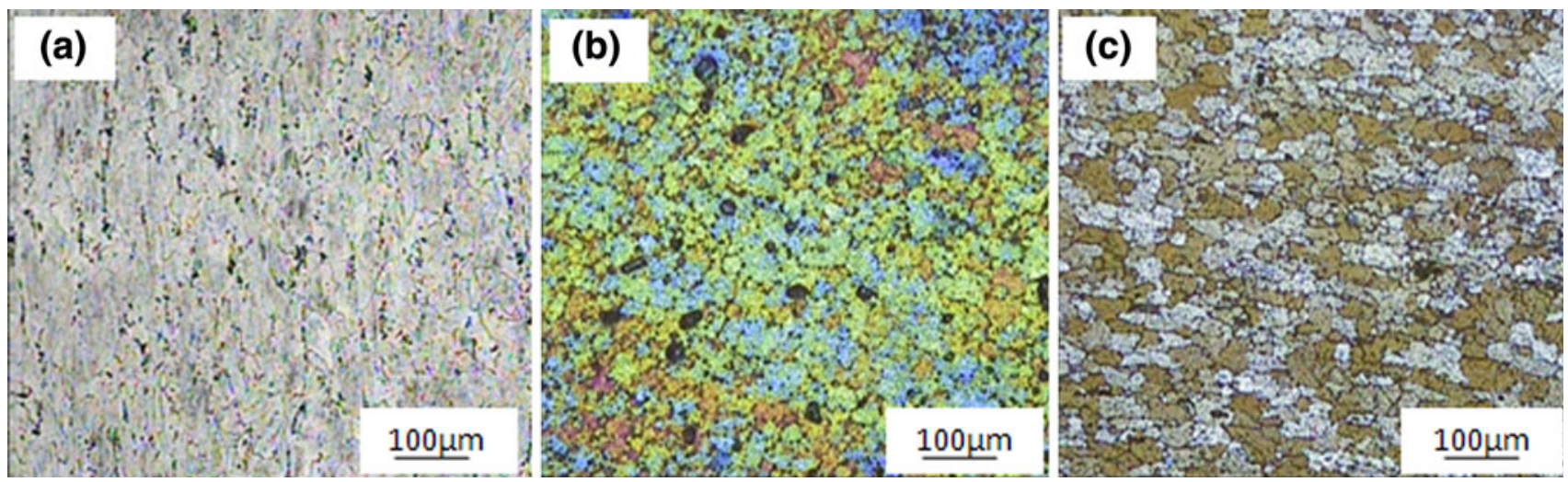

Fig. 1 Microstructures of Al 5083-O with different reagents. a Keller's etch, b Weck's etch, and c new technique
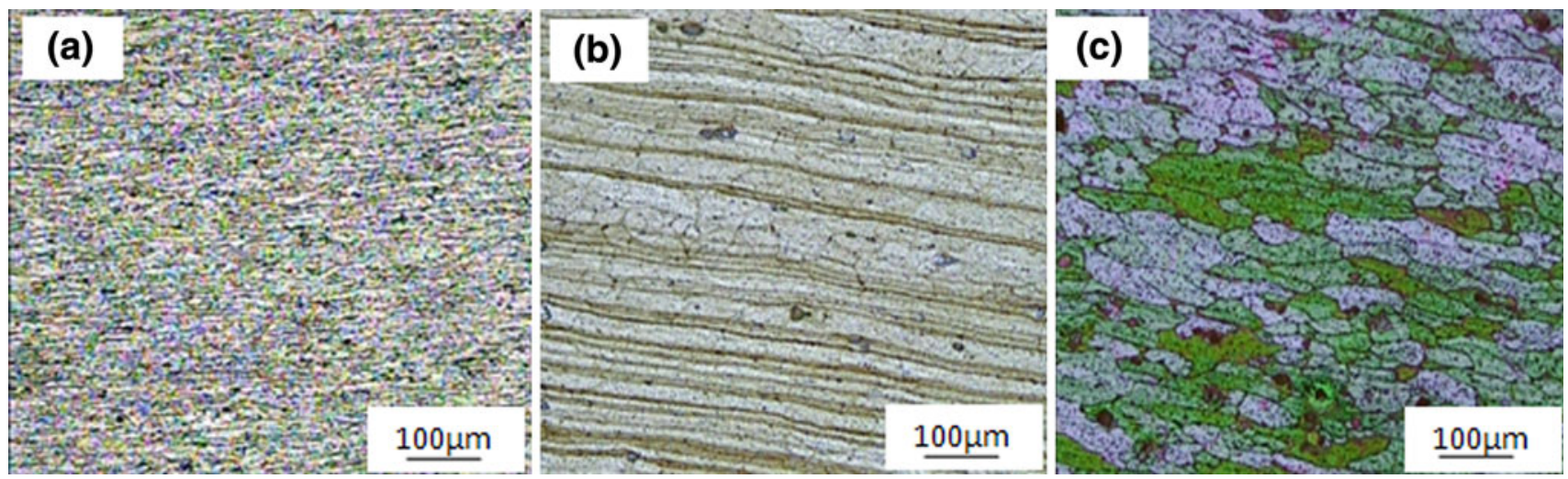

Fig. 2 Microstructures of Al 5083-30\% cold work with different reagents. a Keller's etch, b Weck's etch, and c new technique

examined in a light microscope. The same samples were also etched under optimum conditions for respective reagents in Keller's $\left(190 \mathrm{~mL} \quad \mathrm{H}_{2} \mathrm{O}+5 \mathrm{~mL} \quad \mathrm{HNO}_{3}\right.$ $(65 \%)+3 \mathrm{~mL} \mathrm{HCl}(32 \%)+2 \mathrm{~mL} \mathrm{HF}(40 \%))$ and Weck's reagents to compare results with the new technique.

Microstructures of 5083-O, 5083-30\% cold worked and 2024-O and 2024-T6 alloys are shown in Figs. 1, 2, 3, and 4 , respectively. The new technique shows a uniform response to grain boundaries in 2000 and 5000 series aluminum alloys, and demonstrates a favorable comparison with the other reagents. The combined etchant reaction is attributed to:

(a) The effect of the pre-etchant on precipitates and grain boundaries in these alloys. (b) The influence of Weck's reagent to produce a positive effect on grain contrast.

The advantage of this technique, in comparison with techniques used by other researchers [3], is that it does not need the use of polarized light and sensitive tint, or a heat treatment that may alter the microstructure.

\section{Conclusion}

A new metallographic technique has been developed for revealing the grain structures of common 2000 and 5000 series aluminum alloys. This technique consists of two steps: 


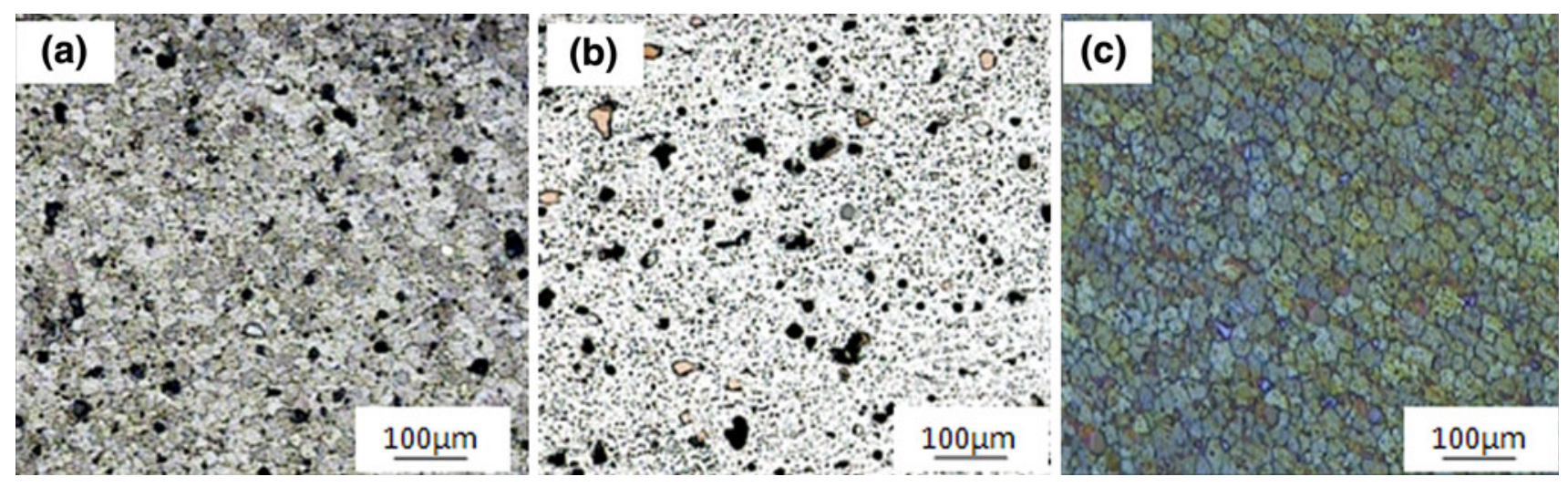

Fig. 3 Microstructures of Al 2024-O with different reagents. a Keller's etch, b Weck's etch, and c new technique
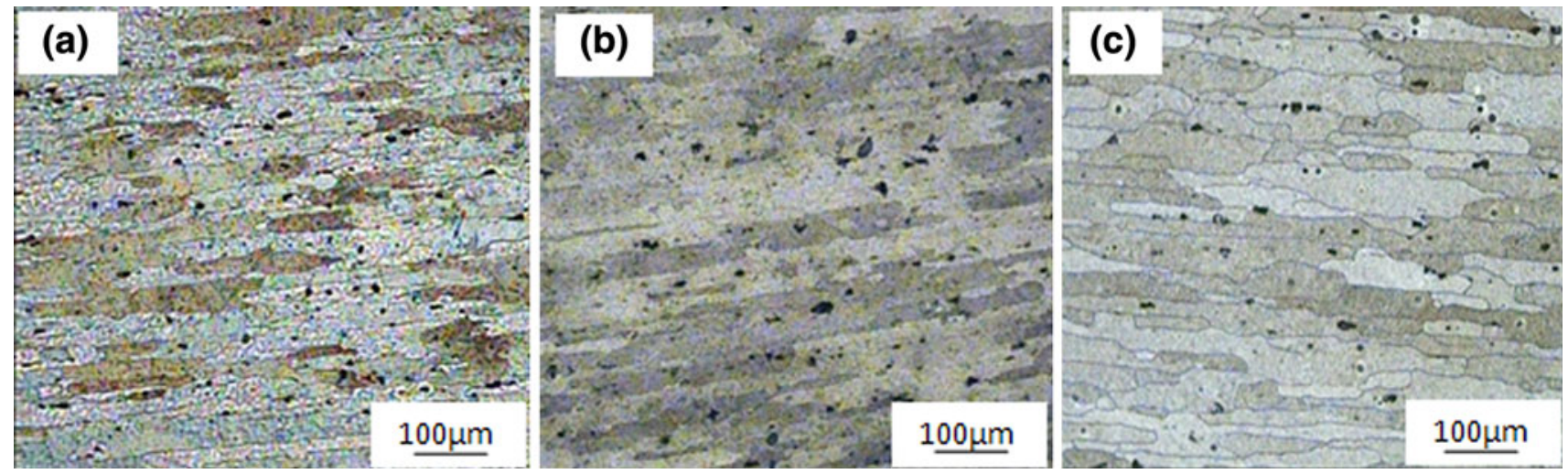

Fig. 4 Microstructures of Al 2024-T6 with different reagents. a Keller's etch, b Weck's etch, and c new technique

1. Three minutes pre-etch with a solution of: $1 \mathrm{~g} \mathrm{NaCl}$ in $50 \mathrm{~mL} \mathrm{H}_{3} \mathrm{PO}_{4}(40 \%)$ at $70{ }^{\circ} \mathrm{C}$, and

2. Etch with Weck's reagent: $100 \mathrm{~mL} \mathrm{H}_{2} \mathrm{O}+1 \mathrm{~g}$ $\mathrm{NaOH}+4 \mathrm{~g} \mathrm{KMnO}_{4}$.

The grain contrast of samples prepared with the new technique is superior to any existing etching technique reported in the literature. This technique will make grainsize measurements easier, more accurate, and more amenable to automated systems. The two-part concept may also be applicable to other aluminum alloys and aluminum metal matrix composites.

\section{References}

1. W.R. Graff, D.C. Sargent, A new grain-boundary etchant for aluminum alloys [short communication]. Metallography 14, 69-72 (1981)

2. Metallographic Technique for Aluminum and its Alloys, Metals Handbooks (American Society for Metals, Metals Parks) 44073-0002

3. H.S. Yang, A new light optical metallographic technique for revealing grain structures of common 2000,5000, and 7000 series aluminum alloys. Mater. Charact. 38, 165-175 (1997) 